\title{
O aproveitamento lúdico da linguagem e nuances de emancipação na literatura infantil contemporânea
}

\author{
Fabiano Tadeu Grazioli ${ }^{1}$ \\ Universidade Regional Integrada do Alto Uruguai e das Missões, Campus de Erechim, Erechim, RS, Brasil.
}

A vaca presepeira, livro literário para a infância de João Paulo Hergesel, ou simplesmente JP, foi vencedor da 14. ${ }^{\text {a }}$ edição do Prêmio Barco Vapor, realizada em 2018. O prêmio, idealizado pelas Edições SM, prevê a participação de autores brasileiros, que podem inscrever originais de textos narrativos para crianças e adolescentes. JP, paulista, morador de Alumínio (SP), foi vencedor de outros concursos literários, como o Cancioneiro Poético, do Instituto Piaget/Portugal, o Concurso Monteiro Lobato de Contos Infantis, do Serviço Social do Comércio (SESC) do Distrito Federal e o Prêmio Ganymedes José de Literatura Infantil e Juvenil, da União Brasileira dos Escritores (UBE).

O autor é doutor em Comunicação, mestre em Comunicação e Cultura e licenciado em Letras. Publicou dezenas de obras para crianças e jovens, mas a obra anunciada receberá a nossa atenção pois, como a imprensa noticiou na época da divulgação do resultado do prêmio, "desbancou" mais de mil originais. JP, com 25 anos, venceu uma concorrência disputada por autores conhecidos, alguns com carreira consolidada na literatura infantil e juvenil no País. Cabe, no espaço que dispomos, propormos algumas reflexões sobre a elaboração de $A$ vaca presepeira, além da observação do modo como ela ressoa em sua linguagem e seu enredo em estudos importantes da crítica da literatura infantil que têm servido para avalizar a pertinência do uso de alguns recursos na construção de obras para a criança, bem como atestado a pertinência de narrativas para esse público.
Juno é uma vaca presepeira, ou seja, no Natal, trabalha no presépio da fazenda. O leitor esperava que ela recebesse esse adjetivo por viver se metendo em presepadas. Mas não deixa de ser por isso também. A brincadeira revelada pela ambiguidade do título e pela invencionice que a palavra "presepeira" ganha quando a relacionamos ao presépio (esse significado não existe no dicionário), já dá uma ideia do tom lúdico da obra, tanto na utilização na linguagem, quanto na maneira de que construir o enredo. Mas, para que possamos refletir com mais clareza posteriormente sobre a linguagem, voltamos ao enredo. Todo Natal, Juno participa do presépio, junto com os outros animais da fazenda. Contudo, o seu sonho mesmo é ser rena do Papai Noel. Na tarde do dia de Natal daquele ano, Juno fez uma tentativa frustrada de voar. Havia caído na lama e recebido xingamento do porco. Quase se atrasou para o presépio. O burro, ouvindo em plena encenação a sua lamentação - ela preferia participar daquela data puxando o trenó do bom velhinho -, instiga a amiga dizendo que, se fosse realmente o seu sonho, ela deveria procurar o Papai Noel no Polo Norte. Quem sabe, usando a magia natalina, o barbudo não a fazia voar e, assim, realizaria o seu desejo. A ideia parecia muito interessante, mas Juno não sabia como conseguir dinheiro para comprar uma passagem tão cara. O burro sugeriu que ela trabalhasse em outras épocas do ano, não somente no Natal, quando tinha emprego garantido no presépio. Chegada a meia-

ORCID: http://orcid.org/0000-0002-3860-6767. E-mail: tadeugraz@yahoo.com.br 
-noite, os animais comemoraram mais um Natal. No outro dia, Juno tratou de procurar emprego na cidade. Primeiro, a negativa. Mas, depois, situações inventivas e engraçadas levam-na a trabalhar no Carnaval, na Páscoa e nas festas juninas. Os animais da fazenda também colaboraram com a quantia que ainda faltava. A soma daria para comprar a passagem. Mas, no aeroporto, foi perseguida pelos guardas, afinal, vacas não viajam em aviões. Precisou fugir e foi parar no asfalto, onde encontrou um grupo de cavalos romeiros, com quem foi até o México, já que se tratava de um país do Hemisfério Norte. "As palavras 'Hemisfério Norte' eram tudo o que Juno precisava ouvir! Se o México ficava ali, deveria ser perto do Polo Norte e, se a cavalaria ia para lá, ela poderia ir junto". (HERGESEL, 2018, p. 26).

Já no México, tendo deixado para trás o Brasil, a Colômbia, o Panamá, a Costa Rica, a Nicarágua, as Honduras e a Guatemala, Juno aproximou-se de um grupo de cachorros que foram os responsáveis por lhe explicar a confusão que ela havia feito entre Hemisfério Norte e Polo Norte. Um deles, Carlos, que usava um tapa-olho, propôs-lhe uma aventura pelo ar, em um balão de ar quente, chegando até Miami, nos Estados Unidos, e uma aventura mais ousada ainda pelo mar, nadando com uma baleia, até o Polo Norte. Lá chegando, Juno enfrenta a burocracia, já que não tinha reunião agendada com o Papai Noel, e o desprezo das renas, que a ridicularizam por ser uma vaca e querer puxar o trenó do bom velhinho. Mas o deboche das renas não desconstruiu aquilo que a protagonista já carregava dentro de si:

Juno colocou o cérebro para funcionar e, assim como seu amigo burro, refletiu sobre a sua história. Ela podia não voar como as renas, nem ter o nariz vermelho, porém fazia coisas que as renas não faziam.

Era determinada. Procurava realizar sempre o melhor nas suas profissões e na luta pelos seus sonhos. Mesmo que fosse apenas uma peça a mais no teatro de fim de ano, era a protagonista da própria história.

Além disso, sabia que tinha força necessária para puxar trenós. Provavelmente nenhuma ali estivesse apta para desfilar no Carnaval, fazer ovos de chocolate e doces de festa junina, atravessar o mundo em romarias, balões e baleias. Juno podia se considerar única, e isso a levou a sorrir novamente (HERGESEL, 2018, p. 39-40).

Uma avalanche carregou as renas, Carlos e Juno para o pé da montanha. A vaca e o cachorro livraram-se da neve com facilidade, mas a rena de nariz vermelho, justamente a mais arrogante, afundava-se cada vez mais na neve e pedia por socorro. Suas colegas, por mais que tentassem, não conseguiam removê-la. Juno sugeriu que voasse, como fazia, com tanta competência, à frente do trenó. A rena então confessou-lhe que ela e as colegas voavam somente na noite de Natal, quando recebiam encantamento do Papai Noel para arrastarem o trenó mundo afora. A vaca, então, para salvar a rena, derreteu a neve que a envolvia com seu bafo quente, o mesmo que utilizava para aquecer o menino Jesus na encenação do presépio. Foi nesse momento que o Papai Noel apareceu e disse saber da história de cada habitante do planeta, inclusive a de Juno. Só que lamentava por não poder dar a ela o cargo de rena, já que ela era uma vaca. Triste, procurando o caminho de volta, o bom velhinho pediu que esperasse. Deixou claro que não podia oferecer-lhe o cargo de rena legítima, mas ela poderia ser uma ajudante, como vaca mesmo, nos países do Hemisfério Sul, inclusive no Brasil, lugares nos quais faz calor na época do Natal.

Muitas vezes, um texto pertinente à criança é caracterizado pela sua adequação ao público leitor que deseja atingir. Essa premissa determinará o quanto uma obra literária consegue se aproximar da criança na atualidade, ou então renegá-la, rejeitá-la. A estrutura e a linguagem da obra somam-se na tentativa de estabelecer a maior comunicação possível dentro de um quadro de referências que vai desde o conhecimento da língua pela criança até a sua compreensão e aceitação dos recursos expressivos e lúdicos da linguagem literária. Sobre esse último (e fundamental) componente da obra literária para a criança, Fernando Azevedo, importante pesquisador português, afirma que a literatura “[...] com que a 
criança interagirá é constituída por textos susceptíveis de emanciparem o imaginário dos seus recetores mais jovens e de lhes permitirem reencontrar o uso lúdico, pessoal e criativo da linguagem" (AZEVEDO, 2014, p. 16). À medida que os projetos literários que visualizam a criança como receptora pretendem ser emancipatórios, eles necessitam fazer uso lúdico, pessoal e criativo da linguagem. Nessa perspectiva, Azevedo ainda acrescenta:

Se do ponto de vista da expressão, e no quadro dos códigos e convenções predominantes no sistema semiótico literário, ele se caracteriza por um recurso frequente à oralidade, pelo carácter não muito extenso dos seus textos e a predominância de elementos reiterativos, é em particular na linguagem e na incessante liberdade que os seus usos lúdicos possibilitam que encontramos uma das grandes marcas que o especificam (AZEVEDO, 2014, p. 16).

Marca do sistema semiótico literário endereçado à infância, o uso lúdico da linguagem coloca criadores e leitores em interseção criativa e leva a criança a adentar no referido sistema. Em A vaca presepeira, julgamos oportuno investigar brevemente como o autor utiliza tal recurso a favor da construção da narrativa e da possibilidade de inserir a criança no sistema semiótico literário. O próprio título da obra, comentado anteriormente, já é uma provocação que tem base no uso lúdico, pessoal e criativo da linguagem. Passemos a outros exemplos retirados do texto:

Juno se concentrou, centrou o popozão com duas reboladinhas e se embolou num plano muito bem encaminhado. Caminhou até o pé de acerola, acelerou até o ribeiro e correu pela margem da água corrente, sem imagem do destino. Destruía todas as paredes de brisa que apareciam na sua frente (HERGESEL, 2018, p. 9).

A semelhança sonora e lexical de palavras como "concentrou" e "centrou", "reboladinhas" e "embolou", "encaminhado" e "caminhou", "acerola" e "acelerou", "correu e corrente" contrastam com os significados diferentes que elas ganham no texto de JP. Ao colocar essas palavras lado a lado no primeiro parágrafo do texto, o jogo lúdico é estabelecido à medida que elas se aproximam no léxico e no som, mas se distanciam semanticamente. Abrindo o texto dessa forma, o autor já prepara o leitor para a experiência que está iniciando: não fosse a situação narrada, inusitada e engraçada - afinal, Juno insiste em voar -, a linguagem com que procederá à narração dos fatos também tem valor. Obviamente JP não constrói as quarenta e sete páginas de seu texto com o jogo cuidadoso de que lançou mão no primeiro parágrafo. O uso lúdico da linguagem apontado por Azevedo fica evidente nesse exemplo e em muitos outros momentos do enredo.

Refletindo sobre os modos como JP tira a linguagem de seu uso comum e a utiliza em "modo lúdico", notamos, além da que descrevemos no parágrafo anterior, que o autor, muitas vezes, reescreve uma frase ou palavra de conhecimento público, trazendo um significado já conhecido em uma nova elaboração, seja da frase, seja da palavra. Assim nascem, inclusive, muitas palavras novas no texto, ou melhor: a nova utilização de muitas palavras na escrita do autor. Outros modos simplesmente não têm classificação e são invencionices de quem parece divertir-se ao escrever. A título de exemplo: quando Juno tenta voar (investimento para o qual o primeiro parágrafo do texto é preparação) e cai em uma poça de lama, os animais da fazenda comentam:

- Será que, no planeta de onde ela vem, é normal ter vaca atolada?

- E há quem diga que quem não tem avião voa com vaca...

- Só não vou zoar porque seria muito vaca-nagem da minha parte!

(HERGESEL, 2018, p. 10, grifo do autor).

A brincadeira que o personagem faz, ao comparar Juno, atolada na lama, com o prato conhecido como vaca atolada, dá ao primeiro comentário o tom lúdico a que aludíamos anteriormente. Já no segundo comentário, há a reescritura do ditado popular "quem não tem cão caça com gato", bem aos moldes da história, que tem como protagonista uma vaca que 
pretende voar. No terceiro comentário, a palavra “vaca-nagem”, que até foi grafada pelo autor em itálico, é uma brincadeira com a palavra sacanagem, mais uma vez contextualizando a palavra já conhecida na história da vaca protagonista. Notemos que o trabalho lúdico, aqui, pode parecer simplista, mas não é. Há esmero do autor em jogar com as palavras, as frases e o contexto da história que ele cria, por isso não são construções que caberiam em qualquer história, elas derivam de um enredo que, por sua vez, as autoriza, contextualiza e lhes dá significado. Perceber o uso da linguagem, nesse sentido, também é trabalho que exige afinco por parte do leitor, que precisa compactuar deste universo criado pelo ficcionista e entender de que modo ele está autorizado a compreender esses investimentos criativos.

A narrativa é permeada de outros exemplos que poderíamos trazer aqui. Mas queremos encerrar a exemplificação com um fragmento que aposta no conhecimento de mundo da criança para, a partir dele, investir no aspecto lúdico da linguagem:

- E agora? O que eu faço? Como vou realizar meu sonho de ser rena do Papai Noel?

- Rena? - ironizou um dos membros da gangue de quatro patas. - Só se for vaca-rena!

Os outros cães desembestaram a dançar enquanto enrolavam a língua:

- Lá-lá-lá-lá, vaca-rena! Eh, vaca-rena! (HERGESEL, 2018, p. 29).

O fragmento joga com a música Macarena, conhecida no Brasil desde 1996, também sucesso entre as crianças da época. Obviamente o leitor contemporâneo não acompanhou o auge do sucesso da música, mas, por compartilhar a cultura musical de diferentes épocas e gerações, conhece a letra e a coreografia. É isso que permite compactuar com a brincadeira que JP propõe no fragmento transcrito, no qual os cachorros inventam a palavra vaca-rena, referindo-se a música.

Teresa Colomer, no importante estudo A formação do leitor literário: narrativa infantil e juvenil atual, investiga as características de um número significativo de obras para a infância e a juventude publicadas na Espanha, no período de 1977 a 1990.
Segundo a autora, uma parte muito pequena da produção dos anos 1990, mas muito importante do ponto de vista teórico, assimilou os principais aspectos da teoria crítica associada ao pós-modernismo. E alguns pesquisadores aplicaram, efetivamente, esse instrumento de descrição da cultura atual à análise do corpus infantil e juvenil. É o caso de Anita Moss, cujo estudo foi utilizado por Colomer na primeira parte de sua obra. Moss chegou à conclusão de que nos livros infantis os autores utilizam alguns tipos de ruptura em relação às normas tradicionais. Do conjunto de características que Colomer discute em seu estudo a partir de Moss, interessa-nos a última, a saber: os jogos com as palavras, por encontrarmos sintonia entre ela e a construção da obra em análise. Ao descrever os jogos com palavras, Colomer afirma:

\begin{abstract}
A cultura atual explicita e ressalta a construção do mundo através da linguagem e sua arbitrariedade. Concordando com isso, muitos autores brincaram de inventar novas linguagens [...], de maneira que o texto propõe-se a jogar com a forma pela qual a linguagem constrói o mundo e mostrá-la claramente em sua qualidade de sistema arbitrário de signos. (COLOMER, 2003, p. 111).
\end{abstract}

Já assinalamos, a partir de Azevedo, que $A$ vaca presepeira faz uso lúdico da linguagem. Também é importante observarmos o texto na perspectiva que Colomer, a partir de Moss, propõe e, nesse sentido, cabe registrar que os exemplos que já trouxemos à nossa escrita demostram o modo que JP encontra de jogar com novas maneiras de apresentar nuances da linguagem que são caras à criança, insinuando um universo que funciona nos contornos do uso lúdico e não dicionarizado das palavras, recorrendo muitas vezes ao conhecimento partilhado com o mundo adulto, e tantas outras vezes à cultura anterior à da infância letrada, época do predomínio dos recursos da oralidade, como da poesia folclórica e da brincadeira, ou até da cultura de massa, como a musical.

A utilização dos verbos "brincar" e "inventar" por Colomer no fragmento dão-nos a dimensão que a ruptura verificada por Moss, no início da década 
de 1990 , teve em relação à literatura tradicional endereçada à criança. Se antes não era viável que os autores libertassem o texto da regularidade e da pontualidade do uso pragmático da linguagem, os investimentos nos jogos com palavras - tão próximos da infância, tão representativos dessa fase da vida e da maneira natural com que a criança lida com o código que vai, aos poucos, conhecendo e dominando - representaram uma tomada de posição frente a uma literatura que nem sempre dialogou em pé de igualdade com o seu destinatário. JP reporta-se, na elaboração de $A$ vaca presepeira, ao significado que os verbos "brincar" e "inventar" possuem na sua sinonímia mais simples e corriqueira; tais verbos demonstram-se absolutamente imbricados na obra, a ponto de não conseguirmos proceder com uma separação lógica dessas duas ações no texto, tal qual a criança, que não sabe explicar ao adulto quando brinca ou quando inventa. Para o autor, inventar parecer ser brincar e vice-versa, tanto no nível da construção da linguagem, quanto no nível da invenção do enredo. Dessa maneira, em A vaca presepeira, JP potencializa uma característica apontada há pelo menos 30 anos pelos estudiosos da literatura para crianças e que ainda tem espaço como recurso para a construção das obras na atualidade.

Regina Zilberman, interessada na representação na literatura infantil, do adulto e da criança no contexto da família, formulou uma tipologia composta por três modelos teóricos: o eufórico, o crítico e o emancipatório, resultado da análise das narrativas infantis produzidas no Brasil, desde as primeiras décadas do século XX até a década de 1980, época do desenvolvimento do estudo. Juno não é personagem humana, nem possui família, mas nem por isso deixa de apresentar características que a associam a um dos modelos propostos por Zilberman, o emancipatório, justamente aquele que é considerado pela pesquisadora o mais favorável ao crescimento e a autonomia do leitor. Nesse modelo, o escritor, "recusando a intermediação dos pais na relação entre a criança e a realidade, coloca seus heróis numa posição de autonomia em relação a uma instância superior e dominadora". (ZILBERMAN, 2003, p. 215). Juno, como já afirmamos, não é personagem humana e não possui família, mas o seu criador a coloca em uma posição de autonomia em relação às situações que desempenham o papel de instância superior e dominadora e que aparecem na sua vida de um Natal a outro. Precisa lidar, primeiramente, com a própria autoimagem, muitas vezes prejudicada pela ideia incutida em sua mente de que será uma vaca de presépio para sempre, ideia que ela se esforça para afastar de seus pensamentos em diversos momentos da narrativa (é claro que não tem nada de errado em continuar sendo uma vaca de presépio, mas a protagonista, como já salientamos, tem outro sonho); com o paradigma de não conseguir voar, afinal, é uma vaca; com a falta de dinheiro para viajar ao Polo Norte; com o fato de não ser aceita nos aviões; com a ausência de discernimento sobre questões básicas como a diferença entre o Polo Norte e o Hemisfério Norte, o que, no enredo, gera uma grande confusão; com a carência de empatia das renas do Papai Noel, que ridicularizam seu sonho; ou com desastres que fogem ao controle das personagens, como a avalanche que surpreende o cachorro Carlos, as renas e a protagonista, entre outas situações. Esses impasses, tomados como percalços na trajetória de Juno (e todos eles superados), é importante registrar, representam, em alguma medida, a posição de autonomia da protagonista assinalada por Zilberman como compatível com o modelo emancipatório.

É de se esperar que, no modelo de que estamos tratando, os autores dos enredos busquem a emancipação da criança perante os condicionamentos que os adultos impõem a elas. Juno toma o lugar da criança na obra de JP, e os obstáculos que supera, chamados acima de instância superior e dominadora, são as amarras do mundo adulto colocadas no enredo de uma maneira mais pitoresca. Ali estão, como que travestidas, as forças que a protagonista precisa vencer, para que, fora do contexto que lhe é conhecido (a fazenda e o presépio), ela enfrente, com postura interrogadora, os desafios de sua história. Ao retornar ao Brasil, bem como sugere Zilberman no modelo emancipatório, Juno reforça a importância de sua experiência longe da fazenda, realizando-se como vaca na entrega de 
presentes para as crianças brasileiras e de outros países de Hemisfério Sul, sem reconhecer, como sugere a pesquisadora, a superioridade do lugar de origem. Isso, sabemos, para que a experiência vivida longe de casa tenha a devida importância na história, e também na vida da criança que se identificará com a personagem e suas aventuras.

\section{Referências}

AZEVEDO, Fernando. Literatura infantil e leitores: da teoria às práticas. 2. ed. Raleigh, N. C.: Lulu Press, 2014.

COLOMER, Teresa. A formação do leitor literário: narrativa infantil e juvenil atual. Tradução de Laura Sandroni. São Paulo: Global, 2003.

HERGESEL, João Paulo. A vaca presepeira. Ilustrações de Taisa Borges. São Paulo: Edições SM, 2018.

ZILBERMAN, Regina. A literatura Infantil na Escola. 11. ed. São Paulo: Global, 2003. https://doi.org/10.11606/va.voi14.50376

Recebido em: 16/7/2019.

Aprovado em: 23/9/2019.

\#34871

SEÇÃO: RESENHAS

\section{Fabiano Tadeu Grazioli}

Universidade Regional Integrada do Alto Uruguai e das Missões (URI), Campus de Erechim (RS), Erechim, RS, Brasil

Orcid: http://orcid.org/0000-0002-3860-6767

E-mail: tadeugraz@yahoo.com.br

Endereço de correspondência: Rua Eduardo Stefanos Zaar, 1051. Bairro Colégio Agrícola. Erechim/RS. CEP: 99714-304 